\title{
Photoperiod-dependent modulation of anti-Müllerian hormone in female Siberian hamsters, Phodopus sungorus
}

\author{
Esther W Kabithe and Ned J Place \\ Department of Population Medicine and Diagnostic Sciences, College of Veterinary Medicine, Cornell University, \\ Ithaca, New York 14853, USA \\ Correspondence should be addressed to N J Place; Email: njp27@cornell.edu
}

\begin{abstract}
Fertility and fecundity decline with advancing age in female mammals, but reproductive aging was decelerated in Siberian hamsters (Phodopus sungorus) raised in a short-day (SD) photoperiod. Litter success was significantly improved in older hamsters when reared in SD and the number of primordial follicles was twice that of females held in long days (LD). Because anti-Müllerian hormone (AMH) appears to inhibit the recruitment of primordial follicles in mice, we sought to determine whether the expression patterns of AMH differ in the ovaries and serum of hamsters raised in SD versus LD. Ovaries of SD female hamsters are characterized by a paucity of follicular development beyond the secondary stage and are endowed with an abundance of large eosinophilic cells, which may derive from granulosa cells of oocyte-depleted follicles. In ovaries from 10-week-old SD hamsters, we found that the so-called 'hypertrophied granulosa cells' were immunoreactive for $\mathrm{AMH}$, as were granulosa cells within healthy-appearing primary and secondary follicles. Conversely, ovaries from age-matched LD animals lack the highly eosinophilic cells present in SD ovaries. Therefore, AMH staining in LD was limited to primary and secondary follicles that are comparable in number to those found in SD ovaries. The substantially greater AMH expression in SD ovaries probably reflects the abundance of hypertrophied granulosa cells in SD ovaries and their relative absence in LD ovaries. The modulation of ovarian AMH by day length is a strong mechanistic candidate for the preservation of primordial follicles in female hamsters raised in a SD photoperiod.
\end{abstract}

Reproduction (2008) 135 335-342

\section{Introduction}

The mammalian ovary is endowed with a limited number of germ cells, and at any given point in a female's lifetime, the number of primordial follicles represents the resting pool of oocytes from which she can draw upon for future reproductive efforts (Hirshfield 1994). Continuous activation, or recruitment, of primordial follicles over time results in their numerical decline with age, and in women, menopause ensues when near or complete exhaustion of ovarian follicles occurs (Faddy \& Gosden 1996). Several hormones and factors have been shown to modulate primordial follicle activation and most of these have been found to be stimulatory (reviewed by Fortune 2003). Conversely, there is convincing evidence that anti-Müllerian hormone $(\mathrm{AMH}$, also known as Müllerian inhibiting substance or MIS) suppresses primordial follicle activation via autocrine and paracrine effects (Durlinger et al. 1999, 2002a). Until relatively recently, AMH was best known for its expression in the Sertoli cells of developing testes and the regression of the Müllerian ducts in males during sexual differentiation (Jost 1947). However, differentiated ovaries also produce $\mathrm{AMH}$ and the granulosa cells of growing preantral follicles appear to be the principal source (Ueno et al. 1989, Hirobe et al. 1992, Baarends et al. 1995, Durlinger et al. 2002a, 2002b).

In female Siberian hamsters (Phodopus sungorus), short-day (SD) conditions profoundly inhibit reproductive physiology and development (Ebling 1994, Adam et al. 2000), and the number of ovarian primordial follicles appears to be influenced by the photoperiod in which females are reared (Place et al. 2004, Timonin et al. 2006). Because AMH suppresses primordial follicle activation, we investigated the effects of day length on ovarian $\mathrm{AMH}$ expression in Siberian hamsters. Ovaries from females held in SD have an unusual feature granulosa cells from preantral follicles appear to luteinize following atresia of the oocyte (van den Hurk et al. 2002, Place et al. 2004, Timonin et al. 2006) and the histology of these luteinized granulosa cells is consistent with continued steroidogenic activity (van den Hurk et al. 2002, Place et al. 2004). To determine whether these granulosa cells continue to express $\mathrm{AMH}$ after oocyte atresia, we performed immunohistochemistry on ovaries from hamsters raised in either SD or long days (LD). Luteinized granulosa cells of atretic follicles within SD ovaries were 
immunoreactive for $\mathrm{AMH}$ and because these cells account for a substantial portion of the SD ovary's volume, we predicted $\mathrm{AMH}$ protein expression would be greater in whole ovaries from SD when compared with LD hamsters.

Circulating levels of $\mathrm{AMH}$ decline with age, which may reflect the age-associated depletion of ovarian follicles (Kevenaar et al. 2006). Interestingly, serum $\mathrm{AMH}$ concentrations correlate with the number of ovarian primordial follicles in mice (Kevenaar et al. 2006) and women (Bath et al. 2003). Measurement of serum AMH concentration may be a useful marker when assessing a woman's probability of success when considering assisted reproductive technologies that require gonadotropin stimulation and collection of preovulatory oocytes (e.g., in vitro fertilization; van Rooij et al. 2005). The number of primordial follicles within ovaries from Siberian hamsters raised in SD was approximately twice the number seen in age-matched LD ovaries (Place et al. 2004, Timonin et al. 2006), thus we measured serum AMH concentrations to test our prediction that circulating AMH would be higher in SD than in LD hamsters.

\section{Results}

\section{Body, uterine, and paired ovarian mass}

When animals were killed at 10 weeks of age, females held in LD weighed significantly more than SD females. Uterine mass and paired ovarian mass were also greater in LD than in SD females (Table 1). Based on body, uterine, and paired ovarian mass, none of the SD females appeared to be photononresponders.

\section{Ovarian histology and immunohistochemistry}

Ovarian histology was noticeably different in females raised in SD when compared with LD. Antral follicles were commonplace and corpora lutea $(\mathrm{CL})$ were often present in LD (Fig. 1A), but not SD ovaries (Fig. 1B; Table 2). Follicle development rarely advanced beyond the secondary stage in SD ovaries, and the SD ovary was also characterized by an abundance of hypertrophied eosinophilic cells, which surround atretic oocytes (Fig. 1B).

Table 1 Body, uterine, and paired ovarian mass in Siberian hamsters reared in long or short days.

\begin{tabular}{lccr}
\hline & $\begin{array}{c}\text { Long day } \\
(n=7)\end{array}$ & $\begin{array}{c}\text { Short day } \\
(n=7)\end{array}$ & P value \\
\hline Body mass (g) & $29.8 \pm 1.2$ & $20.8 \pm 1.2$ & $0.002^{\mathrm{a}}$ \\
Uterine mass (mg) & $126.1 \pm 26.2$ & $15.0 \pm 4.1$ & $<0.001^{\mathrm{b}}$ \\
Paired ovarian mass (mg) & $9.7 \pm 0.4$ & $6.4 \pm 0.7$ & $0.003^{\mathrm{a}}$
\end{tabular}

astudent's t-test.

Median test.
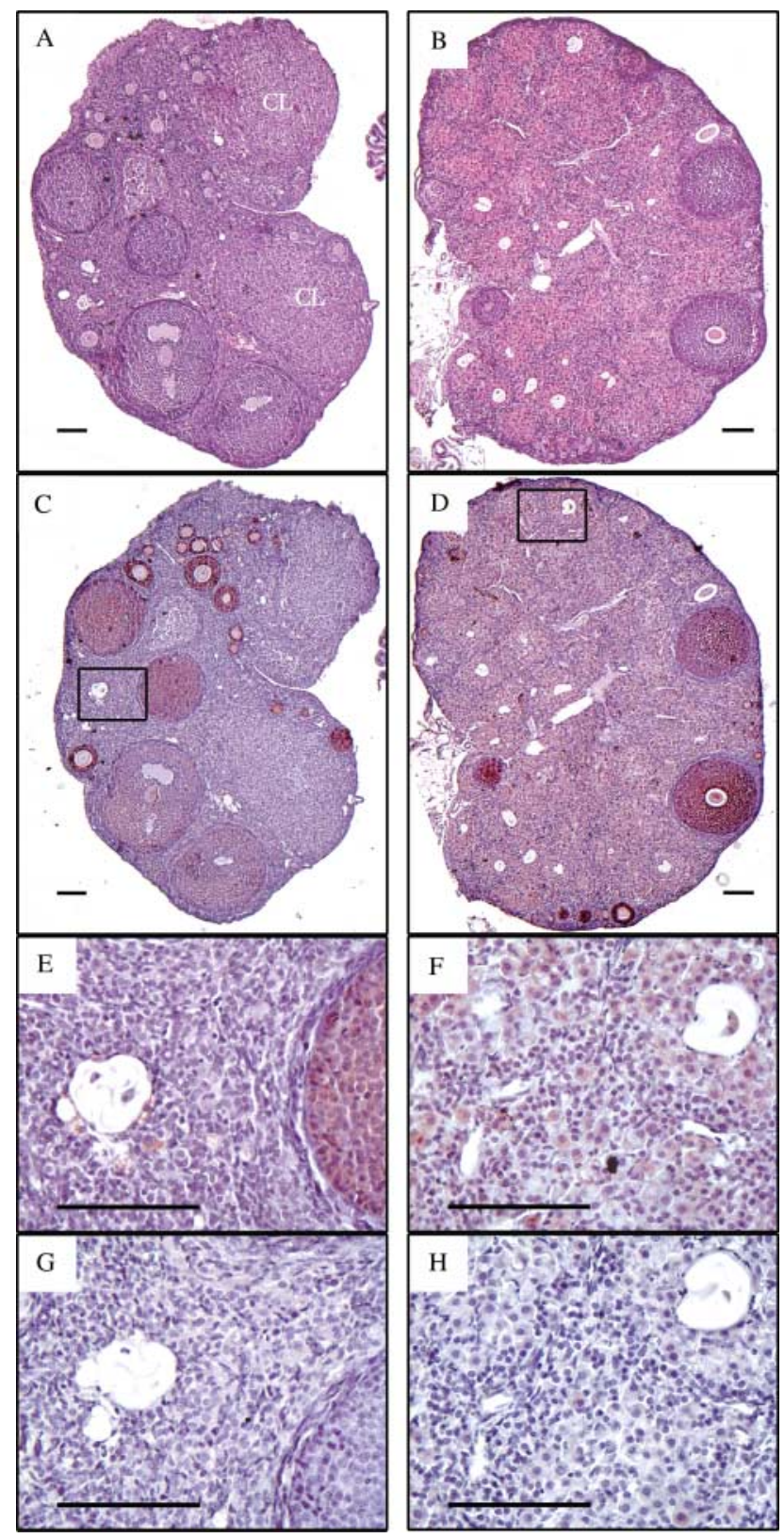

Figure 1 Photomicrographs of ovaries from Siberian hamsters held in either long days (LD; A, C, E and G) or short days (SD; B, D, F and $\mathrm{H})$ from conception to 10 weeks of age. (A and B) Hematoxylin and eosin staining. Corpora lutea $(\mathrm{CL})$ were seen only in $\mathrm{LD}$ ovaries. (C and D) Immunhistochemistry for anti-Müllerian hormone (AMH) showing the most intense staining in granulosa cells in primary and secondary follicles. (E and F) Higher magnification of boxed regions in $\mathrm{C}$ and $\mathrm{D}$ showing oocyte remnants and cells that surround them. Granulosa cells surrounding atretic oocytes in SD (F) have hypertrophied (luteinized) and stain positive for $\mathrm{AMH}$, in contrast to comparable cells in LD ovaries (E). ( $G$ and $H$ ) Sections adjacent to those shown in $\mathrm{E}$ and $\mathrm{F}$ for which the primary antibody against $\mathrm{AMH}$ was preincubated with the blocking peptide (refer to Materials and Methods for details). Bars $=100 \mu \mathrm{m}$. 
Table 2 Ovarian follicle counts in Siberian hamsters reared in long or short days.

\begin{tabular}{|c|c|c|c|c|c|}
\hline \multirow[b]{2}{*}{ Day length } & \multirow[b]{2}{*}{ Primary } & \multicolumn{2}{|c|}{ Secondary } & \multirow[b]{2}{*}{ Antral } & \multirow[b]{2}{*}{ Corpora lutea ${ }^{a}$} \\
\hline & & Types 4 and $5 a$ & Type 5b & & \\
\hline Long (16L) & $25.2 \pm 3.6$ & $17.3 \pm 2.1^{*}$ & $6.8 \pm 0.9$ & $2.2 \pm 0.5^{b}$ & $3 / 6$ \\
\hline Short (10L) & $34.3 \pm 4.5$ & $8.2 \pm 1.8$ & $4.8 \pm 1.5$ & $0.3 \pm 0.2^{\mathrm{c}}$ & $0 / 6$ \\
\hline
\end{tabular}

*Long day significantly greater than SD $(P<0.05)$.

${ }^{a}$ Number of females in each group that had at least one corpus luteum.

${ }^{\mathrm{b}}$ Five out of six LD females had at least one antral follicle.

${ }^{\mathrm{C}}$ Two out of six SD females had one antral follicle, the remaining four females had none.

Granulosa cells within primary and secondary follicles in both LD and SD ovaries showed the most intense staining for $\mathrm{AMH}$ following immunohistochemistry (Fig. 1C and D). The AMH seemed to be less intense in the granulosa cells of antral follicles and absent in $\mathrm{CL}$ (Fig. 1C). AMH staining of moderate intensity was seen in the hypertrophied, or 'luteinized', granulosa cells that surround atretic oocytes in SD ovaries (Fig. 1F), whereas the cells surrounding atretic oocytes in LD ovaries were neither luteinized nor positive for AMH (Fig. 1E). Preincubation of the antisera for $\mathrm{AMH}$ with blocking peptide before immunohistochemistry (Fig. 1G and $\mathrm{H}$ ) confirmed the specificity of the AMH staining in the luteinized granulosa cells in SD ovaries. Nonspecific $\mathrm{AMH}$ staining was not seen in negative controls, i.e., when the primary or secondary antibody was omitted or when normal serum was used in substitution for the primary antibody (not shown). AMH immunohistochemistry of neonatal Siberian hamster testes revealed staining limited to Sertoli cells, as expected (not shown).

Because the most intense $\mathrm{AMH}$ staining was seen in primary and secondary follicles, we counted the numbers of these types of follicles and found greater numbers of small secondary follicles (types 4 and $5 a$ ) in LD when compared with SD ovaries, but no significant difference in the numbers of primary or large secondary (type 5b) follicles (Table 2).

\section{Western blots}

Western blot for $\mathrm{AMH}$ protein showed a single band in both LD and SD ovaries at the expected size $(\sim 70 \mathrm{kDa}$; Fig. 2A). Whereas $\mathrm{AMH}$ expression was minimal to moderate in LD ovaries, $\mathrm{AMH}$ in $\mathrm{SD}$ ovaries was consistently moderate to high. Mean AMH protein level relative to $\beta$-actin expression was more than threefold higher in SD than in LD ovaries (Fig. 2B). Because CLs can occupy a substantial volume of LD ovaries and do not express $\mathrm{AMH}$ (Fig. 1A and $\mathrm{C}$ ), we tried to determine whether the presence of CLs in the ovary, as determined by histology, predicted lower AMH expression by Western blot in the contralateral ovary. With small sample sizes (three LD ovaries with CLs and three without), which limited statistical power, we could detect no clear association between the presence or the absence of CLs and $\mathrm{AMH}$ expression of the ovary as a whole.

\section{Serum AMH ELISA}

Despite higher $\mathrm{AMH}$ protein expression in the ovaries of SD females, serum AMH concentration was significantly lower in SD than in LD females $(t=3.00 ; P=0.01$; Fig. 3). The correlation $(r=-0.353)$ between ovarian and serum $\mathrm{AMH}$ was not significant $(P=0.09)$. As with ovarian $\mathrm{AMH}$, the presence or the absence of CLs in ovaries of LD females did not seem to overtly impact serum AMH concentration (LD with CL: $3.7 \pm 0.6 \mathrm{ng} / \mathrm{ml}$, $n=3$; LD without $\mathrm{CL}: 3.4 \pm 0.4 \mathrm{ng} / \mathrm{ml}, n=3$ ).

\section{Discussion}

Siberian hamsters raised in SD demonstrate a profound inhibition of somatic and reproductive development (Ebling 1994, Place et al. 2004, Timonin et al. 2006), and the ovarian morphology of SD females is proving to be very interesting. Because $\mathrm{AMH}$ has been shown to
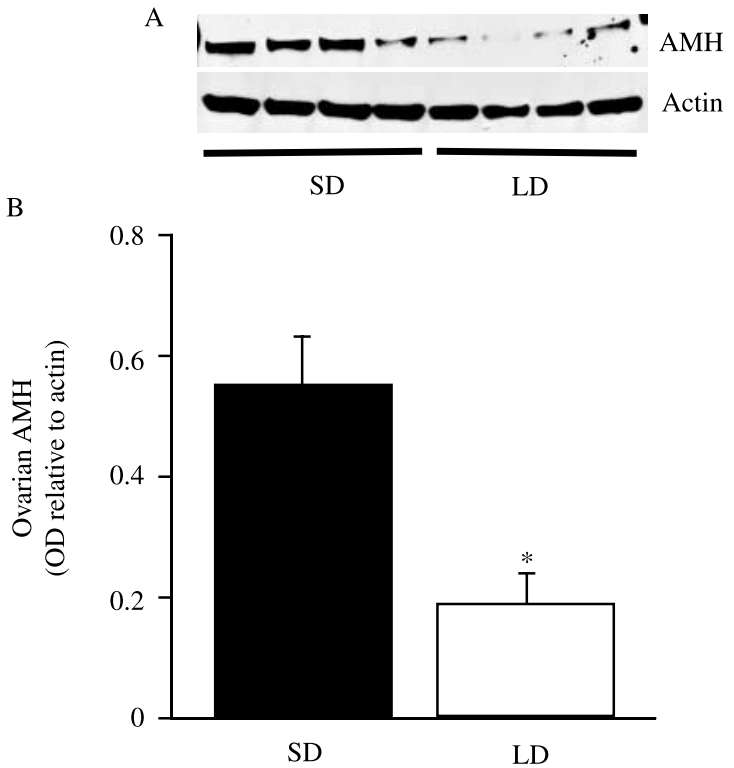

Figure 2 (A) Representative Western blots of ovarian homogenates from Siberian hamsters held in either long days (LD) or short days (SD) from conception to 10 weeks of age. Anti-Müllerian hormone (AMH) and $\beta$-actin were blotted for each ovary, and the optical density of $\mathrm{AMH}$ bands are expressed relative to $\beta$-actin. (B) Mean (+ S.E.M.) AMH optical density for SD (filled bar) and LD (open bar) oaries ( $n=7$ for each group); *denotes significant effect of photoperiod. 


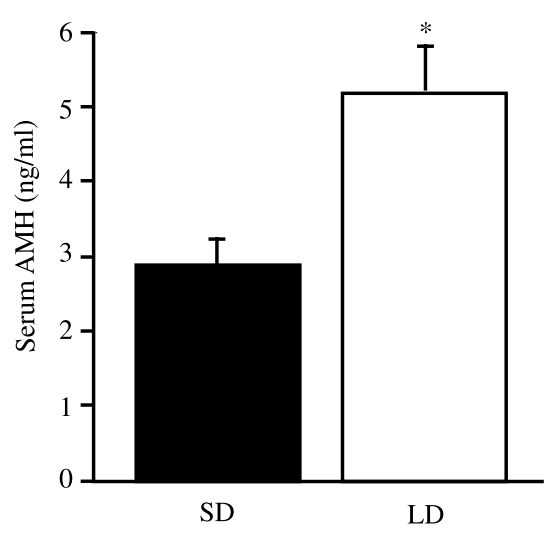

Figure 3 Mean (+S.E.M.) serum AMH concentration ( $\mathrm{ng} / \mathrm{ml}$ ) in SD (filled bar) and LD (open bar) females ( $n=7$ for each group); ${ }^{*}$ denotes significant effect of photoperiod.

inhibit primordial follicle activation (Durlinger et al. 1999, 2002a) and SD female hamsters had significantly more primordial follicles than age-matched LD hamsters (Place et al. 2004), we postulated that ovarian $\mathrm{AMH}$ might be modulated by photoperiod. The threefold higher AMH levels in SD when compared with LD ovaries are an attractive mechanistic candidate for the preservation of primordial follicles and deceleration of reproductive aging in female hamsters raised in SD. However, the findings of the present study represent correlation and not causation. Nevertheless, these initial results are a good starting point for elucidating the means by which day length influences the numbers of primordial follicles and reproductive aging in $P$. sungorus (Place et al. 2004).

Lower AMH concentration in the serum of SD when compared with LD females suggests that the actions of $\mathrm{AMH}$ on primordial follicle activation may be paracrine or autocrine in nature, as proposed by others (Ingraham et al. 2000, Durlinger et al. 2002b, Knight \& Glister 2006). The disparity between ovarian and serum AMH levels in LD and SD hamsters may reflect the variation in their ovarian morphology. For example, differences in the vascularization of SD and LD ovaries may explain the discrepancy. Ovaries from 10-week-old SD females weighed significantly less than LD ovaries (Timonin et al. 2006, present study, Table 1) and thus SD ovaries may be less vascular. In fact, granulosa cells within ovarian follicles form an avascular layer (Irving-Rodgers \& Rodgers 2000) and the $\mathrm{AMH}$-expressing hypertrophied granulosa cells, which account for much of the SD ovary's volume (Fig. 1C), appear to be luteinized but lack the increased vascularity that characterizes CL. Female hamsters raised in SD had more primordial follicles than age-matched LD females (Place et al. 2004, Timonin et al. 2006), and because Kevenaar et al. (2006) found circulating $\mathrm{AMH}$ to correlate with the size of the primordial follicle pool in mice, we expected serum $\mathrm{AMH}$ to be higher in SD than in LD females. SD hamsters showed an advantage over LD females in primordial follicle numbers at 13 and 26 weeks of age (Place et al. 2004), and a preliminary determination of the serum AMH concentration in animals from that study revealed lower $\mathrm{AMH}$ in $\mathrm{SD}$ at 13 weeks of age but higher $\mathrm{AMH}$ in SD at 26 weeks of age (unpublished). We have interpreted these results with caution because the serum samples used had undergone a thaw-refreezethaw cycle before AMH determination. Nevertheless, it appears the relationship between the primordial follicle reserves and circulating $\mathrm{AMH}$ concentration in Siberian hamsters may be more complex than in mice, and day length may be a modulating factor. Differences in reproductive state may also contribute to the lower serum $\mathrm{AMH}$ levels in SD when compared with LD hamsters. Some years ago, serum AMH was reported to be barely detectable or extremely low in prepubertal women (Hudson et al. 1990, Lee \& Donahoe 1993), but these investigators used an ELISA with limited sensitivity $(0.5 \mathrm{ng} / \mathrm{ml})$. The sensitivity of newer ELISAs has improved $(0.006 \mathrm{ng} / \mathrm{ml})$ and a more recent study has reported appreciable levels of $\mathrm{AMH}$ in the serum of infants and young girls (Sir-Petermann et al. 2006). However, these same investigators measured higher levels in peripubertal girls (Crisosto et al. 2007), which suggest that serum $\mathrm{AMH}$ is relatively low in females before puberty. Thus, lower serum AMH concentration in 10-week-old SD hamsters may simply reflect their prepubertal state, but still, the underlying etiology remains unknown.

Because we found that LD ovaries had a comparable or greater number of the follicle types that express $\mathrm{AMH}$ most intensely (types 4 and 5) when compared with SD ovaries (Table 2), we suspect the greater AMH expression seen in SD ovaries by Western blot probably reflects the contribution made by the $\mathrm{AMH}$-expressing luteinized granulosa cells. Alternatively, AMH expression may be up-regulated in granulosa cells that are affiliated with healthy follicles in SD ovaries. Why granulosa cells in SD ovaries persist and luteinize while they surround an atretic oocyte remains to be determined. A similar phenotype has been seen in mice deficient in growth differentiation factor-9 (GDF9) in that granulosa cells within primary follicles luteinized when the oocyte underwent atresia (Elvin et al. 1999). Those investigators did not assess $\mathrm{AMH}$ expression in the luteinized granulosa cells from GDF9 deficient mice, but the luteinized cells were positive for some luteal markers (e.g., luteinizing hormone (LH) receptor and P450 side chain cleavage (P450scc)) as well as nonluteal markers (e.g., inhibin $\alpha$ and P450 aromatase (P450arom)). We did not detect $\mathrm{AMH}$ expression in the Siberian hamster $\mathrm{CL}$ (Fig. 1C), which means the luteinized granulosa cells in SD ovaries express at least one nonluteal marker. In contrast to the GDF9-deficient mouse, Kenny et al. (2002a) reported that the luteinized granulosa cells from Siberian hamsters held in SD probably do not express the inhibin $\alpha$-subunit. However, their figures (in situ 
hybridization) do not provide the histological details necessary to clearly distinguish cell and follicle types. Nevertheless, Kenny et al. (2002a) found significantly lower levels of inhibin $\alpha$-subunit in ovaries from SD versus $\mathrm{LD}$ females.

The intense eosinophilia of the luteinized granulosa cells within hamster SD ovaries suggests that they are active in steroidogenesis, and van den Hurk et al. (2002) reported especially strong enzyme activity for $3 \beta$ hydroxysteroid dehydrogenase in what they referred to as 'hypertrophied granulosa cells of luteinized atretic follicles'. The P450arom activity or expression has not been investigated in SD hamster ovaries, but van den Hurk et al. (2002) found that serum estradiol $\left(E_{2}\right)$ concentration was significantly higher in SD than in LD female hamsters on postnatal days 28, 56, and 80 . Whether luteinized granulosa cells account for the higher circulating $E_{2}$ via P450arom activity remains to be determined. However, the higher serum $\mathrm{E}_{2}$ concentration reported for SD female hamsters (van den Hurk et al. 2002) seems paradoxical and warrants confirmation. The uterus, a highly estrogen sensitive organ, weighs significantly less in female hamsters raised in SD when compared with LD (Ebling 1994, Place et al. 2004, Timonin et al. 2006; present study, Table 1), and we have recently confirmed this finding (unpublished results) at all ages for which van den Hurk et al. (2002) reported significantly higher serum $\mathrm{E}_{2}$ levels in SD females. Moreover, Scotti et al. (2007) used the same commercial RIA kit as van den Hurk et al. (2002) to measure serum $E_{2}$ in Siberian hamsters held in LD and SD, except Scotti et al. (2007) performed a diethyl ether extraction of steroids before proceeding with the RIA. Scotti et al. (2007) found no significant effect of photoperiod on serum $E_{2}$ concentration; however, their SD hamsters were adults that had been transferred from LD to SD, whereas van den Hurk et al. (2002) transferred hamsters from LD to SD at birth. Because $E_{2}$ has been purported to both inhibit (Baarends et al. 1995, Balla et al. 2003) and stimulate (Ikeda et al. 2002) ovarian AMH expression, it will be important to determine whether P450arom is expressed by luteinized granulosa cells and whether hamsters raised in $\mathrm{SD}$ in fact have higher serum $\mathrm{E}_{2}$ concentrations than females reared in LD. Unfortunately, sample volume limitations precluded us from measuring serum $E_{2}$ in the present study.

The circulating concentration of follicle stimulating hormone (FSH) is lower in female Siberian hamsters when raised in SD when compared with LD (Kenny et al. 2002a), and this may contribute to the differences in ovarian morphology and $\mathrm{AMH}$ expression. Baarends et al. 1995, noted a decrease in ovarian Amh expression following the administration of human recombinant FSH to rats, and Balla et al. (2003) reported an up-regulation of $\mathrm{AMH}$ in ovarian granulosa cells in the follitropin receptor knockout (FORKO) mouse. Similar to SD hamsters in which antral follicles are rare (present study) or absent (Place et al. 2004, Timonin et al. 2006), FORKO mice lack ovarian follicles that develop beyond the preantral stage. However, luteinized granulosa cells have not been reported in the ovaries of FORKO mice, and this may reflect differences in the hormonal milieu when compared with SD hamsters. Plasma LH was elevated in FORKO mice relative to wild type and plasma estradiol was undetectable Balla et al. (2003). Conversely, serum LH concentration has been reported to be much lower in SD than in LD female hamsters (Dodge \& Badura 2002), but $\mathrm{E}_{2}$ concentration does not appear to be consistently lower in SD when compared with LD hamsters (van den Hurk et al. 2002, Scotti et al. 2007; but see Moffatt-Blue et al. 2006). The similarities and differences in the ovarian phenotype of SD hamsters with that of GDF9 deficient and FORKO mice should help direct future investigations to determine the mechanisms/signals that underlie the luteinization of granulosa cells and the up-regulation of $\mathrm{AMH}$ in SD ovaries. Logical starting points will be to examine SD ovary expression of GDF9 as well as GATA4, which mediates the inhibition of AMH via the FSH receptor (Tremblay \& Viger 2001, Balla et al. 2003).

In addition to its inhibitory effects on primordial follicle activation (Durlinger et al. 1999, 2002a), AMH has also been shown to inhibit the growth of preantral and antral follicles in mice (Durlinger et al. 2001), by modulating the sensitivity of growing follicles to $\mathrm{FSH}$ (Visser et al. 2006). The higher AMH expression in SD hamster ovaries may explain the findings reported by Kenny et al. (2002b), whereby the ovarian response to an in vivo gonadotropin challenge (pregnant mare serum gonadotropin, PMSG) was blunted in juvenile SD hamsters relative to LD females. PMSG-induced follicular growth that was not as great in SD when compared with LD females, and SD females could not be induced to ovulate when an LH analog (human chorionic gonadotropin) was administered $48 \mathrm{~h}$ after PMSG. These results are intriguing in light of the recent report that $\mathrm{AMH}$ production by granulosa cells from women with polycystic ovary syndrome (PCOS) was significantly increased when compared with normal ovaries, and this may contribute to the anovulatory phenotype in PCOS (Pellatt et al. 2007).

In conclusion, the profound effect of photoperiod on reproductive function in female Siberian hamsters, and on their ovarian physiology in particular, suggests that this species will be a valuable animal model for the study of ovarian follicle development. The activation of primordial follicles is still a poorly understood phenomenon, and the findings that SD rearing preserves the number of primordial follicles and enhances ovarian AMH expression in P. sungorus adds further support for the critical role that $\mathrm{AMH}$ plays in follicular dynamics. Because we have the potential to dictate when juvenile SD females transition to the LD (mature) ovarian phenotype, simply by transferring them to a LD 
photoperiod, we may be able to better understand the conditions and signals in the ovary that modulate follicle activation and later stages of follicular development.

\section{Materials and Methods}

\section{Experimental animals}

Siberian hamsters from our colony (14 h of light per day, $14 \mathrm{~L}$ ) were transferred to $\mathrm{LD}(16 \mathrm{~L})$ or $\mathrm{SD}(10 \mathrm{~L})$ as breeding pairs to generate females for this study. The time of lights-off was synchronized for all animals to $1700 \mathrm{~h}$ eastern standard time (EST). Animals were originally derived from wild-bred stock obtained from Dr K Wynne-Edwards, Queen's University. Experimental females were weaned on postnatal day 18, placed in polypropylene cages ( $2-4$ siblings/cage), and maintained in the photoperiod in which they were born. Food (Teklad 8626; Harlan Teklad, Madison, WI, USA) and water were available ad libitum. Ambient temperature and relative humidity were held constant between $21^{\circ} \mathrm{C} \pm 5$ and $50 \pm 10 \%$ respectively.

\section{Blood and tissue collection}

Fourteen LD and $14 \mathrm{SD}$ females were given an i.p. overdose of sodium pentobarbital, weighed, and then exsanguinated by retro-orbital bleed at 10 weeks of age. All animals were euthanized during the middle of the light cycle between 1200 and $1400 \mathrm{~h} \mathrm{EST}$. Blood was clotted on ice for at least $1 \mathrm{~h}$ and centrifuged at $1000 \mathrm{~g}$ for $20 \mathrm{~min}$ at $4{ }^{\circ} \mathrm{C}$. Drawn off serum was frozen and maintained at $-80^{\circ} \mathrm{C}$ until assayed for $\mathrm{AMH}$.

Both ovaries were removed from each animal, dissected free of surrounding fat, and weighed on an analytical balance. One of the ovaries, selected pseudorandomly from the right or left side, was placed in protein extraction buffer $(10 \mathrm{mM}$ Tris, $0.5 \mathrm{M}$ $\mathrm{NaCl}, 1 \mathrm{mM} \mathrm{MgCl} 2,0.1 \%$ Triton X-100, 1 tablet $/ 10 \mathrm{ml}$ Complete Mini Protease Inhibitor (Roche)) in preparation for Western blots. The remaining ovaries from six animals in each group were immersed in 10\% buffered formalin for histology and follicle counts, and half of those ovaries, three from each group, were used for AMH immunohistochemistry. Formalin fixation continued overnight at room temperature followed by serial dehydration into $70 \%$ ethanol. Ovaries were embedded in paraffin and serially sectioned at $6 \mu \mathrm{m}$. Every tenth section was stained with hematoxylin and eosin and viewed under $400 \times$ magnification to count the types of ovarian follicles that express $\mathrm{AMH}$ with the greatest intensity, i.e., primary and secondary follicles. Because AMH is principally expressed in granulosa cells, we further subdivided secondary follicles into categories with less than four layers of granulosa cells (types 4 and 5a), or four or more layers of granulosa cells (type 5b) surrounding the oocyte (Pedersen \& Peters 1968). Primary follicles were defined as an oocyte surrounded by a single layer of cuboidal granulosa cells.

\section{Immunohistochemistry for AMH}

Six mid-ovary sections from each of three animals in each group were immunostained for $\mathrm{AMH}$. Sections from LD and SD ovaries were alternately placed on each slide to control for potential staining variability between slides. Adjacent sections were mounted on separate slides for negative controls. After dewaxing and rehydration in a series of ethanols, endogenous peroxides were quenched in hydrogen peroxide $(0.3 \%$ in methanol) for $30 \mathrm{~min}$. Sections were then incubated in $10 \%$ normal rabbit serum diluted in dilution buffer $(0.5 \mathrm{M}$ sodium chloride, $0.01 \mathrm{M}$ phosphate buffer, 3\% BSA, 0.3\% Triton $\mathrm{X}-100)$ for $20 \mathrm{~min}$ at room temperature to block nonspecific binding sites. Polyclonal goat anti-MIS antibody (sc-6886; Santa Cruz Biotechnology, Santa Cruz, CA, USA) was diluted 1:1000 in dilution buffer and incubated with sections for $16 \mathrm{~h}$ at $4{ }^{\circ} \mathrm{C}$. As a negative control, primary antibody was incubated 1:1 overnight with MIS (C-20) blocking peptide (sc-6886P; Santa Cruz Biotechnology) on a rocker at $4{ }^{\circ} \mathrm{C}$ before its application to sections as described above. Additional negative controls excluded the primary or secondary antibody. Sections were incubated with the secondary antibody, biotinylated rabbit anti-goat IgG (Santa Cruz Biotechnology; 1:200 in dilution buffer), for $30 \mathrm{~min}$. Immunoreactivities were visualized by incubating sections with Vectastain Elite $A B C$ Solution (Vector, Burlingame, CA, USA) for 30 min and developed with NovaRed Peroxidase Substrate Solution (Vector) following the manufacturer's instructions. Sections were counterstained with hematoxylin.

\section{Western blot for AMH}

Freshly collected ovaries were homogenized in protein extraction buffer, and protein concentrations were determined with the DC Protein Assay Kit (Bio-Rad). For each sample, $\sim 10 \mu \mathrm{g}$ protein were resolved on a $10 \%$ SDS gel under reducing conditions followed by transfer onto a nitrocellulose membrane (Bio-Rad). The membrane was incubated in SuperBlock Blocking Buffer in TBS (Pierce, Rockford, IL, USA) for $60 \mathrm{~min}$ at room temperature to block nonspecific binding sites. Polyclonal goat anti-MIS antibody (sc-6886; Santa Cruz Biotechnology) was diluted 1:1000 in SuperBlock Blocking Buffer and incubated overnight at $4{ }^{\circ} \mathrm{C}$ on a rocker. Specific binding was detected using horse peroxidase anti-goat secondary antibody (PI-9500; Vector) at a dilution of 1:50 000. Labeled proteins were visualized by SuperSignal West Pico Chemiluminescents Substrate (Pierce) and viewed by autoradiography. Using the direct reprobing method outlined in Liao et al. (2000), the relative intensity of $\mathrm{AMH}$ was determined using $\beta$-actin as the loading control. Briefly, the blot was incubated for $1 \mathrm{~h}$ at room temperature with monoclonal mouse anti- $\beta$-actin (Clone AC150; Sigma) diluted 1:5000 in SuperBlock Blocking Buffer, and then probed for $1 \mathrm{~h}$ at room temperature with goat peroxidase anti-mouse secondary antibody (31430; Pierce) at a dilution of 1:100 000. Labeled proteins were visualized as stated above.

Western blot films were scanned into a Macintosh computer, and the optical density of $\mathrm{AMH}$ and $\beta$-actin was analyzed with imaging processing software (Image) 1.34s; NIH, Bethesda, MD, USA). AMH immunoreactivity was expressed relative to $\beta$-actin for each ovary. 


\section{ELISA for AMH}

AMH was measured in duplicate serum samples using an ELISA produced by Diagnostic Systems Laboratories (Webster, TX, USA). This ELISA was validated for the measurement of $\mathrm{AMH}$ in Siberian hamsters by serially diluting a hamster serum sample in the kit's sample diluent and demonstrating parallelism with the standard curve (range $0.05-15 \mathrm{ng} / \mathrm{ml}$ ). The undiluted sample had a starting concentration of $4.26 \mathrm{ng} / \mathrm{ml}$. All samples were run in a single assay and the intra-assay coefficient of variation was $22.0 \%$. The minimum detection limit of the assay as reported by the manufacturer was $0.006 \mathrm{ng} / \mathrm{ml}$.

\section{Statistical analysis}

Results were analyzed with a commercial statistical program (JMP version 5.1.2; SAS Institute, Cary, NC, USA). LD versus SD comparisons of body and paired ovarian mass were made with t-tests, as were comparisons of ovarian and serum AMH. Uterine mass data were not normally distributed and the LD and SD variances were statistically different, thus the median test was used for the uterine mass comparison. Because our preliminary data included animals from the same litter, we averaged all data from females within the same litter and treated the mean as a single data point. Thus, sample sizes reflect the number of litters represented and litters in both groups contained from one to five females. We repeated all analyses using values from all individuals, and the statistical findings were identical to litterbased analyses. Pearson product-moment was used to determine whether serum AMH concentration (by ELISA) correlated with ovarian $\mathrm{AMH}$ expression (by Western blot). Differences at $P<0.05$ were considered to be significant.

\section{Acknowledgements}

The authors thank the staff of Laboratory Animal Services at Cornell University, and Jackie Belliveau in particular, for the exceptional care of our animals. We also thank Jenifer Criuckshank and two anonymous referees for their helpful comments on the manuscript. The authors declare that there is no conflict of interest that would prejudice the impartiality of this scientific work. This study was supported by $\mathrm{NIH}$ grant HD-050358.

\section{References}

Adam CL, Moar KM, Logie TJ, Ross AW, Barrett P, Morgan PJ \& Mercer JG 2000 Photoperiod regulates growth, puberty and hypothalamic neuropeptide and receptor gene expression in female Siberian hamsters. Endocrinology 141 4349-4356.

Baarends WM, Uilenbroek JT, Kramer P, Hoogerbrugge JW, van Leeuwen EC, Themmen AP \& Grootegoed JA 1995 Anti-Müllerian hormone and anti-Müllerian hormone type II receptor messenger ribonucleic acid expression in rat ovaries during postnatal development, the estrous cycle, and gonadotropin-induced follicle growth. Endocrinology $\mathbf{1 3 6}$ 4951-4962.

Balla A, Danilovich N, Yang Y \& Sairam MR 2003 Dynamics of Ovarian Development in the FORKO immature mouse: structural and functional implications for ovarian reserve. Biology of Reproduction 69 1281-1293.
Bath LE, Wallace WH, Shaw MP, Fitzpatrick C \& Anderson RA 2003 Depletion of ovarian reserve in young women after treatment for cancer in childhood: detection by anti-Müllerian hormone, inhibin B and ovarian ultrasound. Human Reproduction 18 2368-2374.

Crisosto N, Codner E, Maliqueo M, Echiburu B, Sanchez F, Cassorla F \& Sir-Petermann T 2007 Anti-Mullerian hormone levels in peripubertal daughters of women with polycystic ovary syndrome. Journal of Clinical Endocrinology and Metabolism 92 2739-2743.

Dodge JC \& Badura LL 2002 5HT, and 5HIAA dialysate levels within the arcuate nucleus of the hypothalamus: relationship with photoperioddriven differences in serum prolactin and luteinizing hormone in the Siberian hamster. Brain Research 946 171-178.

Durlinger AL, Kramer P, Karels B, de Jong FH, Uilenbroek JT, Grootegoed JA \& Themmen AP 1999 Control of primordial follicle recruitment by antiMüllerian hormone in the mouse ovary. Endocrinology 140 5789-5796.

Durlinger AL, Gruijters MJ, Kramer P, Karels B, Kumar TR, Matzuk MM, Rose UM, de Jong FH, Uilenbroek JT, Grootegoed JA et al. 2001 AntiMüllerian hormone attenuates the effects of FSH on follicle development in the mouse ovary. Endocrinology 142 4891-4899.

Durlinger AL, Gruijters MJ, Kramer P, Karels B, Ingraham HA, Nachtigal MW, Uilenbroek JT, Grootegoed JA \& Themmen AP 2002a Anti-Müllerian hormone inhibits initiation of primordial follicle growth in the mouse ovary. Endocrinology 143 1076-1084.

Durlinger AL, Visser JA \& Themmen AP 2002b Regulation of ovarian function: the role of anti-Müllerian hormone. Reproduction $\mathbf{1 2 4}$ 601-609.

Ebling FJP 1994 Photoperiodic differences during development in the dwarf hamsters Phodopus sungorus and Phodopus campbelli. General and Comparative Endocrinology 95 475-482.

Elvin JA, Yan C, Wang P, Nishimori K \& Matzuk MM 1999 Molecular characterization of the follicle defects in the growth differentiation factor 9-deficient ovary. Molecular Endocinology 13 1018-1034.

Faddy MJ \& Gosden RG 1996 A model conforming the decline in follicle numbers to the age of menopause in women. Human Reproduction $\mathbf{1 1}$ 1484-1486.

Fortune JE 2003 The early stages of follicular development: activation of primordial follicles and growth of preantral follicles. Animal Reproduction Science 78 135-163.

Hirobe S, He WW, Lee MM \& Donahoe PK 1992 Müllerian inhibiting substance messenger ribonucleic acid expression in granulosa and Sertoli cells coincides with their mitotic activity. Endocrinology 131 854-862.

Hirshfield AN 1994 Relationship between the supply of primordial follicles and the onset of follicular growth in rats. Biology of Reproduction $\mathbf{5 0}$ 421-428.

Hudson PL, Dougas I, Donahoe PK, Cate RL, Epstein J, Pepinsky RB \& MacLaughlin DT 1990 An immunoassay to detect human Müllerian inhibiting substance in males and females during normal development. Journal of Clinical Endocrinology and Metabolism 70 16-22.

van den Hurk R, Dijkstra G \& De Jong F 2002 Enhanced serum oestrogen levels and highly steroidogenic, luteinized atretic follicles in the ovaries of the Djungarian hamster (Phodopus sungorus) kept under a short photoperiod from birth. European Journal of Endocrinology 147 701-710.

Ingraham HA, Hirokawa Y, Roberts LM, Mellon SH, McGee E, Nachtigal MW \& Visser JA 2000 Autocrine and paracrine Müllerian inhibiting substance hormone signaling in reproduction. Recent Progress in Hormone Research 55 53-67.

Ikeda Y, Nagai A, Ikeda MA \& Hayashi S 2002 Increased expression of Müllerian-inhibiting substance correlates with inhibition of follicular growth in the developing ovary of rats treated with $E_{2}$ benzoate. Endocrinology 143 304-312.

Irving-Rodgers HF \& Rodgers RJ 2000 Ultrastructure of the basal lamina of bovine ovarian follicles and its relationship to the membrana granulosa. Journal of Reproduction and Fertility 118 221-228.

Jost A 1947 Recherches sur la differenciation sexuelle de I'embryon de lapin. Archives d'Anatomie Microscopique et de Morphologie Expérimentale 36 217-315.

Kenny HA, Bernard DJ, Horton TH \& Woodruff TK 2002a Photoperioddependent regulation of inhibin in Siberian hamsters: I. Ovarian inhibin production and secretion. Journal of Endocrinology 174 71-83. 
Kenny HA, Bernard DJ, Horton TH \& Woodruff TK 2002 $b$ Photoperioddependent regulation of inhibin in Siberian hamsters: II. Regulation of inhibin production and secretion by pregnant mare serum gonadotropin. Journal of Endocrinology 174 85-94.

Kevenaar ME, Meerasahib MF, Kramer P, van de Lang-Born BM, de Jong FH, Groome NP, Themmen AP \& Visser JA 2006 Serum AMH levels reflect the size of the primordial follicle pool in mice. Endocrinology 147 3228-3234.

Knight PG \& Glister C 2006 TGF- $\beta$ superfamily members and ovarian follicle development. Reproduction 132 191-206.

Lee MM \& Donahoe PK 1993 Mullerian inhibiting substance: a gonadal hormone with multiple functions. Endocrine Reviews 14 152-164.

Liao J, Xu X \& Wargovich MJ 2000 Direct reprobing with anti- $\beta$-actin as an internal control for western blot analysis. Biotechniques 28 216-218.

Moffatt-Blue CS, Sury J \& Young KA 2006 Short photoperiod-induced ovarian regression is mediated by apoptosis in Siberian hamsters (Phodopus sungorus). Reproduction 131 771-782.

Pedersen T \& Peters H 1968 Proposal for a classification of oocytes and follicles in the mouse ovary. Journal of Reproduction and Fertilility 17 555-557.

Pellatt L, Hanna L, Brincat M, Galea R, Brain H, Whitehead S \& Mason H 2007 Granulosa cell production of anti-Müllerian hormone is increased in polycystic ovaries. Journal of Clinical Endocrinology and Metabolism 92 240-255.

Place NJ, Tuthill CR, Schoomer EE, Tramontin AD \& Zucker I 2004 Short day lengths delay reproductive aging. Biology of Reproduction 71 987-992.

van Rooij IA, Broekmans FJ, Scheffer GJ, Looman CW, Habbema JD, de Jong FH, Fauser BJ, Themmen AP \& te Velde ER 2005 Serum
antiMüllerian hormone levels best reflect the reproductive decline with age in normal women with proven fertility: a longitudinal study. Fertility and Sterility 83 979-987.

Scotti MA, Place NJ \& Demas GE 2007 Short-day increases in aggression are independent of circulating gonadal steroids in female Siberian hamsters (Phodopus sungorus). Hormones and Behavior 52 183-190.

Sir-Petermann T, Codner E, Maliqueo M, Echiburu B, Hitschfeld C, Crisosto N, Perez-Bravo F, Recabarren SE \& Cassorla F 2006 Increased anti-Mullerian hormone serum concentrations in prepubertal daughters of women with polycystic ovary syndrome. Journal of Clinical Endocrinology and Metabolism 91 3105-3109.

Timonin ME, Place NJ, Wanderi E \& Wynne-Edwards KE 2006 Phodopus campbelli detect reduced photoperiod during development but, unlike Phodopus sungorus, retain functional reproductive physiology. Reproduction $132661-670$.

Tremblay J \& Viger RS 2001 GATA factors differentially activate multiple gonadal promoters through conserved GATA regulatory elements. Endocrinology 142 977-986.

Ueno S, Kuroda T, Maclaughlin DT, Ragin RC, Manganaro TF \& Donahoe PK 1989 Müllerian inhibiting substance in the adult rat ovary during various stages of the estrous cycle. Endocrinology 125 1060-1066.

Visser JA, de Jong FH, Laven JS \& Themmen AP 2006 Anti-Müllerian hormone: a new marker for ovarian function. Reproduction 131 1-9.

Received 19 September 2007

First decision 30 October 2007

Accepted 4 December 2007 